\title{
CytaBOM Regimen
}

National Cancer Institute

\section{Source}

National Cancer Institute. CytaBOM Regimen. NCI Thesaurus. Code C10007.

A chemotherapy regimen consisting of cytarabine, bleomycin, methotrexate, and vincristine for the treatment of non-Hodgkin lymphoma (NHL). 